\title{
Recreational use of offshore wind farms: Experiences and opinions of sea anglers in the UK
}

Tara Hooper*, Caroline Hattam, and Melanie Austen

Plymouth Marine Laboratory, Prospect Place, The Hoe, Plymouth, PL1 3DH

* Corresponding author.

tel: + 44 (0) 1752 633100; email: tarh@pml.ac.uk

\begin{abstract}
The expansion of offshore wind farms (OWFs) is likely to increase conflict with other marine users as different sectors compete for space. There may also be positive interactions, as the artificial reef effects from energy infrastructure have the potential to sustain and enhance fishing opportunities. Recreational sea angling is an important sector within the UK but the experiences and opinions of UK sea anglers with respect to OWFs have not been documented. To address this, an online survey was undertaken with recreational anglers around the UK $(n=199)$. Respondents represented a range of socio-demographic and angling characteristics, although male, more frequent and older fishers as well as club members were overrepresented compared to a 2012 national survey. One quarter of the respondents had fished around the perimeter of or within an OWF, most on multiple occasions, and 73\% of those who had not expressed a willingness to do so in future. Anglers reported both positive and negative effects on catch success when fishing near or within OWFs compared to their experiences of the same site prior to OWF development. Outcomes for individual species were also mixed. Anglers recognised the potential artificial reef effects of OWFs and their role as a "safe haven", particularly due to the exclusion of commercial fishers. Negative perceptions included restricted access, harm to marine wildlife, and visual impact. There is little evidence that OWFs will have a significant economic impact on recreational fishing, as most anglers are unlikely to change their behaviour in response to future developments.
\end{abstract}

\section{Keywords}

Offshore wind energy; recreational sea angling; marine planning

\section{Introduction}

By the end of 2015, more than $12 \mathrm{GW}$ of offshore wind capacity had been installed globally, of which $3.4 \mathrm{GW}$ was installed during 2015 alone [1]. Over $80 \%$ of this capacity is located off the coasts of five countries in northern Europe: the UK and Germany are world leaders with, respectively, 1454 and 792 offshore wind turbines connected to the grid [1]. Growth of the sector is expected to continue at a similar pace. The UK, for example, has an additional 547 turbines in projects at the pre-construction or construction phase [2]. The further expansion of offshore wind farms (OWFs) in the coastal waters of Northern Europe is likely to increase conflict with other marine users as different sectors compete for space. Understanding the interactions between marine activities is a key component of the marine planning process, the application of which is increasing globally. The future growth of marine energy has already been highlighted as an important factor within the UK's marine planning process [3]. 
Interactions between other marine users and OWFs may not necessarily be negative. In particular, sessile benthic organisms will settle on the hard substrate provided by OWF infrastructure (including foundations, cables and their armouring), creating artificial reefs. The refuge and food source provided by these artificial reefs attracts species of importance to commercial and recreational fishing, and so has the potential to support fishing activities [4]. This has been shown to be the case for oil and gas infrastructure in the Gulf of Mexico, where the platforms are regularly utilised by anglers and commercial fishers [5-7].

Evaluation of the impacts of OWFs on fisheries, and the opportunities for co-location of the sectors, has focussed on commercial activity, primarily using workshops and surveys to determine fishers' perceptions of the potential impacts on their industry. This has shown that commercial fishers recognise possible opportunities from OWF developments in terms of alternative employment, creation of marine habitats and improvements in harbour infrastructure, whilst also fearing loss of fishing grounds and income, and holding negative views on the form and content of the consultation process [e.g. 8-11]. Empirical evidence of the extent of the displacement of trawling activities from OWF footprints is also beginning to emerge [12].

There were over 12,000 fishermen employed within the UK's commercial fleet in 2015, and the Gross Value Added from the sector was $£ 604$ million [13]. However, recreational sea anglers are also an important group of marine users: there are an estimated 884,000 sea anglers in the UK, who contribute approximately $£ 2.1$ billion to the economy [14]. The need to understand how the growth in marine energy will affect recreational users of marine space has been identified [3], but there has been no detailed assessment of the implications of OWFs for recreational sea angling in the UK. OWFs in England have been perceived as a potential opportunity for sea anglers, who could profit from the exclusion of commercial fishers from the sites and a possible increase in fish abundance [10]. Conversely, a scenario for Scotland has been postulated in which all sea angling within OWF footprints ceases and is not offset by increased activity elsewhere, resulting in a cost to the sector of $£ 24.5$ million [15]. However, neither study included significant engagement with the recreational angling community: only one angling network [15], and three individuals [10] were consulted. The resulting uncertainty in the evidence used to support the assumptions on which future scenarios were based has been explicitly noted [15].

This paper seeks to address this gap in the existing evidence by providing primary data on the experiences and opinions of sea anglers with respect to OWF development in the UK, and hence provide information relevant to OWF development, marine planning and the sustainable use of marine space.

\section{Method}

An online questionnaire was developed with four sections, the first of which concerned respondents' current angling activities including frequency, location, and target species, while the second section comprised questions on experiences of angling within OWFs. The third section contained a set of questions intended to solicit more general opinions of OWFs such as their wider environmental impacts and role in the energy mix, 
usually via a series of statements to which respondents could express their level of (dis)agreement on a five point Likert scale (with additional "no opinion" and “don't know" response options). Standard background information on gender, age, education, employment and income was also collected in the final section. Openended questions were included in different sections of the survey to allow respondents to expand on previous responses or provide additional information.

The questionnaire included two additional sections for respondents who had previously been sea angling along the south coast of England between Beachy Head and Selsey Bill. This region incorporates the site of the Rampion OWF, which, at the time the survey was implemented, had not yet entered the offshore construction phase. The purpose of these sections was to assess whether sea angling activities would be affected by the OWF development and to consider the economic implications of any changes. The assessment included two contingent behaviour scenarios of i) increased catches and ii) no change in catches as a result of the OWF development. Each respondent completing that section of the questionnaire was randomly allocated only one of the two scenarios. Respondents were asked to report whether the number of trips they would make to the area following OWF construction would increase, decrease or remain the same under the conditions described within the scenario.

The questionnaire was tested face-to-face with sea anglers in Plymouth, before being implemented online between November 2015 and January 2016 with recreational sea anglers around the UK. Web links to the survey were advertised by sea angling clubs (which had been identified through national federations and online searches), angling magazines, and on social media. Participants were also recruited via the angling representatives of Inshore Fisheries and Conservation Authorities (IFCAs; statutory agencies with responsibilities for inshore fisheries and the marine environment), who circulated the web links to their key contacts and angling forums, in newsletters and on their websites. Initial invitations to participate were followed-up with two reminders at approximately monthly intervals.

\section{Results}

\subsection{Demographic and sea angling characteristics}

The survey generated 199 usable responses. The sample included individuals with a range of backgrounds and angling practices (Table 1), although male, more frequent and older anglers were over-represented in comparison to a 2012 national angling survey [14], which provides the most comprehensive national dataset on the demographics of UK sea anglers. The sample of respondents in our survey also contained a higher proportion of anglers who are members of angling clubs, a consequence of the sampling procedure that used clubs as one point of contact to recruit survey participants. Responses were received from around the coast of England and Wales with some representation from Scotland, although most respondents were from southern (and particularly south eastern) England (Figure 1). 
Table 1. Percentage of respondents with particular demographic characteristics, comparing this study to the 2012 UK national angling survey [14]

\begin{tabular}{|c|c|c|c|}
\hline & $\begin{array}{l}\text { This } \\
\text { study }\end{array}$ & 2012 UK national angling survey [14] & \\
\hline Employed & 73 & & - \\
\hline Retired & 23 & & - \\
\hline Household income $>£ 40,000 \mathrm{pa}$ & 53 & & - \\
\hline Angling club member & 67 & & 7 \\
\hline Male & 98 & & 84 \\
\hline \multicolumn{4}{|l|}{ Age } \\
\hline $18-24 \mathrm{yrs}$ & 5 & $16-25 \mathrm{yrs}$ & 11 \\
\hline $25-44 \mathrm{yrs}$ & 24 & $26-45 y r s$ & 39 \\
\hline $45-64 y r s$ & 51 & $46-65 y r s$ & 41 \\
\hline$>64 \mathrm{yrs}$ & 21 & $>65 \mathrm{yrs}$ & 9 \\
\hline \multicolumn{4}{|l|}{ Frequency of fishing activity } \\
\hline Most days & 3 & & \\
\hline 1-3 times per week & 25 & Frequent (9+ days in last $3 \mathrm{mnths})$ & 12 \\
\hline 2-3 times per month & 44 & Regular (4-8 days in last 3mnths) & 24 \\
\hline Once per month & 13 & Occasional ( $2-3$ days in last 3 mnths) & 32 \\
\hline Less than once per month & 13 & Rare ( 1 day in last 3 mnths) & 32 \\
\hline Less than once per year & 3 & & \\
\hline
\end{tabular}

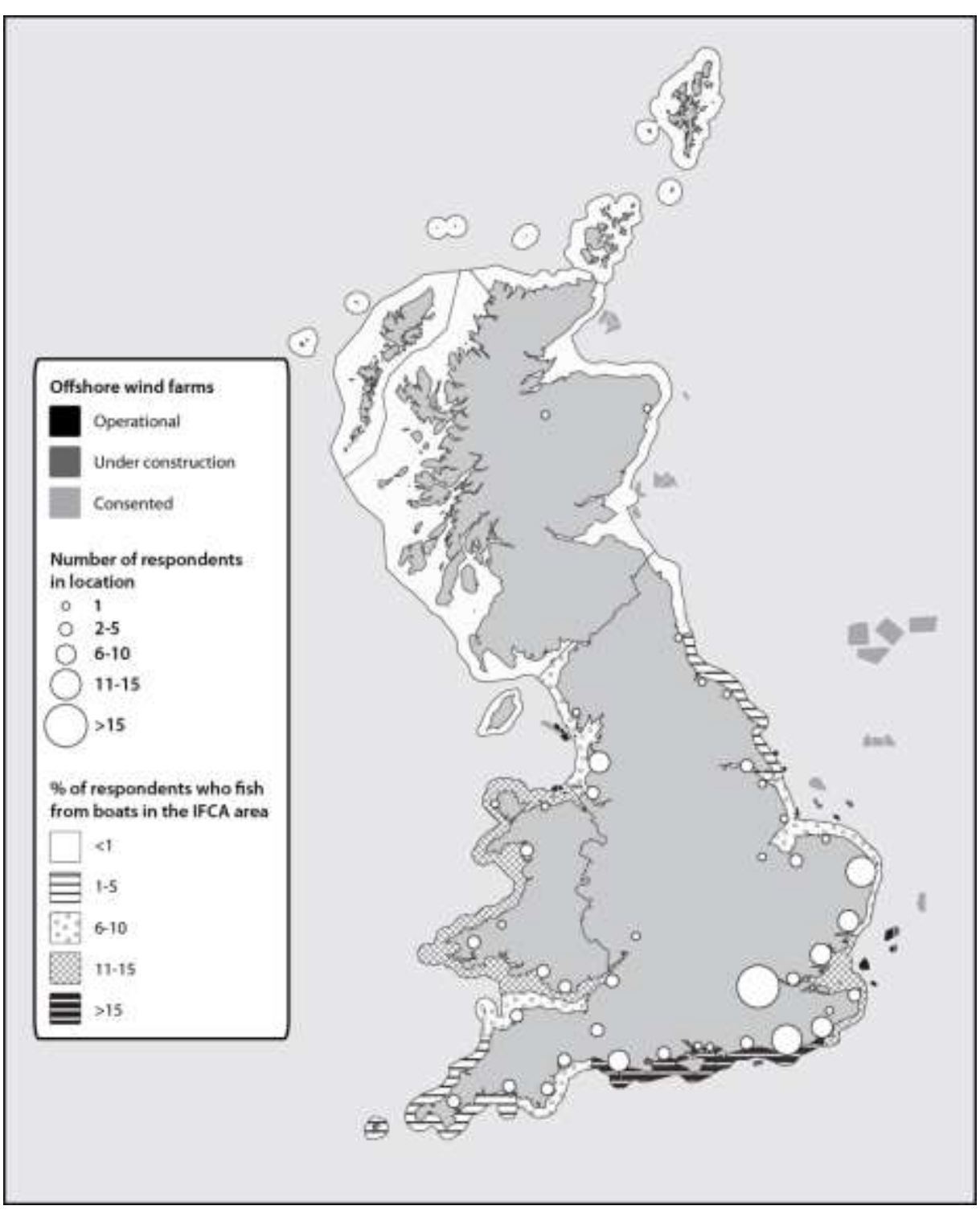

Figure 1. Approximate site of survey respondents' home location and OWF developments, with the proportion of respondents fishing from boats in the different IFCA areas 
OWFs are located some distance from shore and hence are most likely to affect those fishing from boats rather than shore-based anglers. Sixty one percent of respondents reported that they usually fish from boats, of whom almost $40 \%$ fish within the South and Sussex IFCA areas (Figure 1). None of the respondents from Northumberland or Scotland were regular boat users. While the opinions of boat-based anglers in these regions is therefore under-represented, as yet the only major OWF in Scotland is Robin Rigg, which is located in the Solway Firth on the border with England.

The reported distance travelled by those who fish from boats during normal angling activities was, on average, 10 nautical miles offshore. Seventy five percent of existing OWFs are within 10nm of the coast [2], suggesting that distance from shore is not a significant barrier, in principle, to anglers accessing OWFs. Willingness to fish near natural and artificial reefs may also have a bearing on the likelihood of anglers using OWFs as fishing sites, as it serves to indicate whether they value reefs as angling locations and also their perception of the risk of approaching these structures. Over $80 \%$ of the respondents reported that they fished at least sometimes near reefs or artificial structures such as wrecks, while $47 \%$ and $39 \%$ of respondents fished "most of the time" or "always" near reefs and artificial structures respectively.

\subsection{Experience of angling within OWFs}

One quarter of the respondents (50 anglers) had fished around the perimeter of, or within, an OWF, most on multiple occasions. Most of these anglers (74\%) had fished at only one OWF, with Gunfleet Sands (visited by $20 \%$ of respondents), the London Array (9\%), Greater Gabbard (7\%) and Kentish Flats (7\%) the most frequently visited OWFs. The median distance from an individual OWF turbine at which anglers had fished was $100 \mathrm{~m}($ mode $=50 \mathrm{~m})$. There was a range of risk perception amongst respondents, however; three anglers who had fished near an OWF were unwilling to approach closer than $1 \mathrm{~km}$, while 12 anglers (24\%) had fished $25 \mathrm{~m}$ or less from the structure.

The species most commonly caught at OWFs were bass (reported by $62 \%$ of respondents), dogfish (also $62 \%)$, and cod and other whitefish (58\%). Three anglers reported that they had caught nothing. Anglers reported mixed catch outcomes from fishing near or within OWFs compared to their experiences of the same site prior to OWF development. Of the 39 anglers who had fished a site before and after an OWF was constructed, $24 \%$ reported no change in their catches, $33 \%$ reported catches had improved, $36 \%$ a decline and a further $10 \%$ described their catches as having declined initially before improving. Mixed outcomes were also reported for different species, with, for example, some anglers reporting that catches of species such as bass and cod had declined while others noted an improvement in catches of these species. A decline in catches of tope at or near OWFs was reported consistently (by $16 \%$ of respondents, with no reports of unchanged or improved catches of this species), with two anglers attributing this to electromagnetic field (EMF) effects. 


\subsection{Effects of future OWFs}

There was a similar division in opinion as to whether angling activities would be affected by future developments of OWFs or other marine renewable energy devices: $44 \%$ believed that there would be an effect on their angling activities, while $37 \%$ felt future OWFs would have no effect. When responding to an open-ended question on what these effects might be, $23 \%$ of respondents gave responses suggesting they felt that OWFs would probably lead to a positive change, while $16 \%$ felt that OWFs would harm wildlife (through, for example, EMF effects) or otherwise have a negative effect on angling. A quarter of respondents expressed in positive terms the potential artificial reef effects of OWFs, and other statements also suggested that anglers value the role of OWFs as a "safe haven" for fish species, particularly due to the exclusion of commercial fishers from the sites. Conversely, almost $20 \%$ of anglers were concerned that their access to fishing grounds would be restricted if OWFs were built. Other negative perceptions of future OWFs that were not related to wildlife impacts were raised by $9 \%$ of respondents. These included a negative impact on the view, noise disturbance, and navigation and safety issues. Anglers also expressed the need for improved dialogue and consultation during the OWF development process.

The influence of OWF developments on current behaviour was explored in more detail through questions focussing on the south coast between Beachy Head and Selsey Bill and the forthcoming construction of the Rampion OWF. A reduced sample was used for this analysis, as only 57 anglers had visited the relevant area. Of these, 28 received the contingent scenario in which catches increased following the development of the OWF, and 29 received the scenario in which catches remained the same. When asked what they would do in response to an OWF constructed in this area, $86 \%$ of those presented with a scenario in which catches increased as a result of the OWF development reported that they would not change the frequency with which they visit the site, while 7\% would decrease and $7 \%$ increase their visit frequency. Of those presented with the scenario in which the OWF has no effect on catch, $69 \%$ of anglers would not change their behaviour, while $24 \%$ (seven anglers) would reduce the frequency with which they visit the area. Most of these latter respondents would visit an alternative angling site instead.

\subsection{General opinions of OWFs}

Anglers' responses to statements about the potential positive and negative aspects of OWF development showed broad support for OWFs in general: only $27 \%$ would strongly oppose the development of an OWF near where they go angling, and only $20 \%$ agreed that OWFs harm marine wildlife (Figure 2). More than twice as many respondents agreed than disagreed that catches are better at OWFs compared to sandy sea beds, but a large proportion of anglers responded that they did not know. There was also strong agreement that more OWFs are needed to tackle climate change and their deployment would reduce the need for fuel imports. However, about half of the respondents agreed that OWFs spoil the view and negatively affect the wilderness image of the sea, and only $12 \%$ agreed that OWF developers can be trusted to listen to the communities in which they operate. Respondents also had concerns about the cost of energy from OWFs, although again a high proportion of respondents chose the "don't know" option for these questions. 
Sea angling catches are better near

to OWFs than on sandy beds

OWFs have a negative impact on marine wildlife

OWFs spoil the view

OWFs negatively affect the wilderness image of the sea

We need more OWFs to tackle climate change

More OWFs would reduce our need to import fuel

The electricity produced by OWFs is too expensive

OWFs are not viable without subsidies from the government

We should stop building OWFs because they are not reliable

OWF developers can be trusted to listen to local communities

I would strongly oppose an OWF built near where I go angling
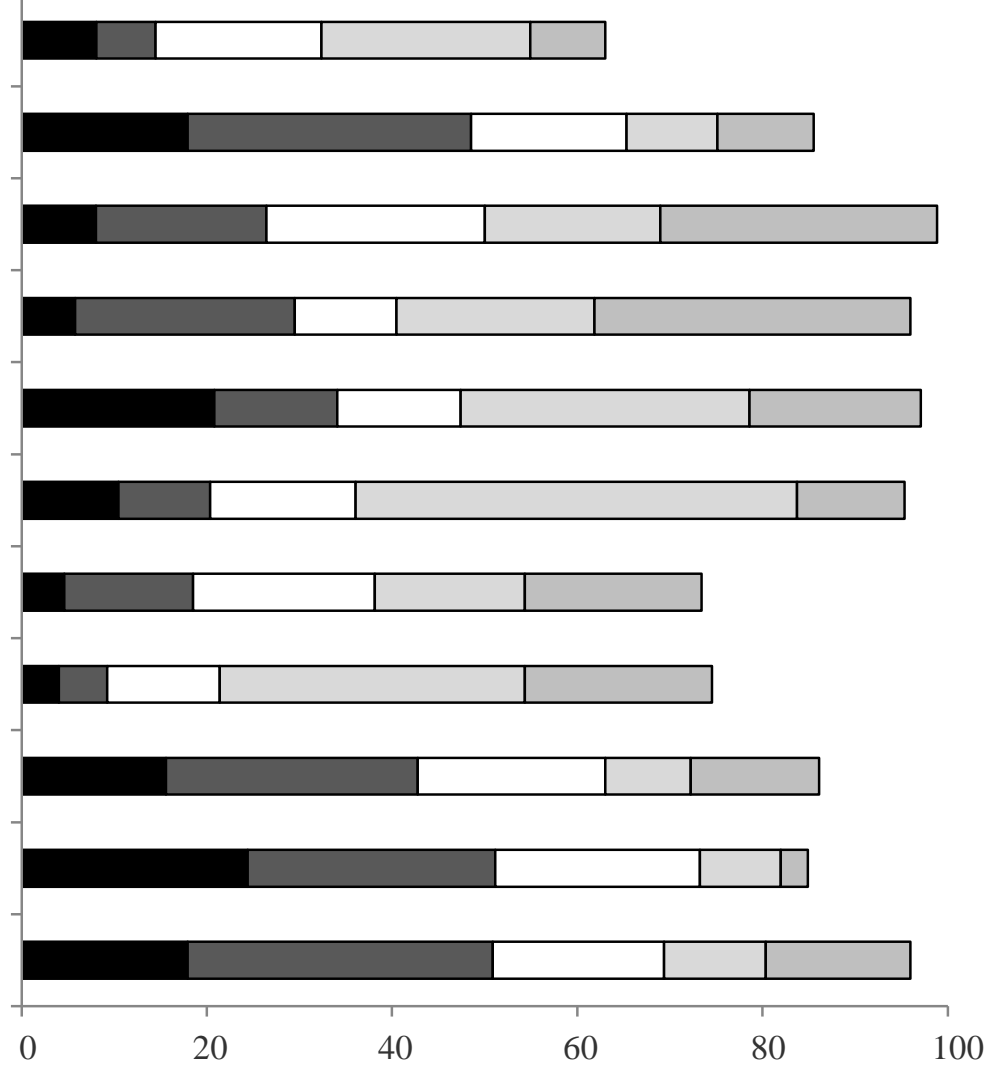

Percentage of respondents

Figure 2. Sea anglers' responses to statements about potential positive and negative impacts of OWFs

The anglers were also asked via an open-ended question if they had any further comments on OWFs, other marine renewable energy or electricity issues more broadly, to which about half of the participants provided a response. Anglers again expressed general support for renewable energy as a necessary part of the energy mix: comments on issues such as the need to reduce carbon emissions and increase energy security accounted for $35 \%$ of responses made. However, a quarter of those responding to that question stated an explicit preference for alternative low-carbon technologies over OWFs, with $14 \%$ preferring nuclear and $12 \%$ tidal energy. Issues raised in earlier questions were also reiterated, including a lack of trust in the Government and in energy companies, negative visual impact and the need for improved information and communication about OWF projects. Respondents also expressed opposition to OWFs on the grounds that they did not provide a consistent, or sufficient, supply of electricity and were a costly option.

\subsection{Factors affecting the likelihood of having fished in OWF sites}

Of those who had not fished around the perimeter of or within an OWF, 73\% expressed a willingness to do so in future. A key factor differentiating between those who had and had not fished at OWF sites was whether there was an OWF located in the angler's usual fishing area: those who had not fished within an OWF were significantly less likely to have a development in their local area $\left(\chi^{2}=16.0, p<0.001\right)$. 
Conversely, risk perception was not a major issue in differentiating between those who had and had not been sea angling at OWF sites. On average, those who had not previously fished near an OWF felt that they could safely approach to a distance of $100 \mathrm{~m}$ from a turbine, which matched the average distance at which those who had used OWF sites actually fished. Furthermore, there was no significant difference between the groups in terms of: i) the regularity at which they fished near other natural and artificial structures such as reefs or wrecks; ii) angling practices such as fishing frequency, usual distance travelled from shore, and club membership; iii) any demographic characteristics; or iv) the likelihood of expressing general opposition to OWF or believing that they spoil the view.

Differences between the groups were, however, detected in terms of certain opinions about OWFs that relate more directly to angling activities. Significantly more of those who had fished near OWFs felt that the developments harmed wildlife $\left(\chi^{2}=5.7, \mathrm{p}=0.017\right)$ and also disagreed that catches were better at OWFs compared to sandy sea beds $\left(\chi^{2}=4.1, \mathrm{p}=0.044\right)$. Responses to these two factors were correlated (Spearman's rho $=0.3137, \mathrm{p}=0.0043$ ). Further analysis of these responses showed that, of the 15 anglers who had fished within an OWF and agreed/strongly agreed that they harm marine wildlife, 12 reported a decline in their catches and a further two an initial decline followed by stabilisation or improvement when commenting about how their catches had changed before and after an OWF development.

\section{Discussion}

In general, sea anglers in the UK have a positive perception of OWFs as an angling resource, as they recognise the potential artificial reef effects and benefits from the exclusion of commercial fishing. A sizeable minority have already fished at OWF sites (usually more than once), and a clear majority of those who have not yet done so expressed an interest in doing so. However, anglers' actual experience of fishing in OWFs was much more mixed. A similar result was found for commercial fishermen: those from South Wales (with no local OWFs) were more positive about OWFs than fishers from the East coast of England where OWFs had already been constructed [8]. As with commercial fishers, the mixed experiences and opinions of sea anglers, coupled with the small sample size, limit the extent to which generalisation can be made about the potential recreational opportunities offered by OWFs.

There is considerable variability in the abundance and distribution of fish stocks at various temporal and spatial scales due to variations in environmental conditions and human pressures. It is, therefore, challenging to determine the impact of OWF developments against this background. During the survey, anglers themselves mentioned that observed declines in catches at OWF sites were in line with general stock changes across the wider region. Conclusive evidence of actual impacts of OWFs on fish stocks remains limited [16] and this continues to be an area requiring further empirical assessment. There is a similarly small volume of literature on the effects of North Sea oil and gas platforms on fish abundance, but this also suggests mixed effects depending on species and site [17-20]. 
However, if OWFs are perceived to have a negative impact on angling opportunities (whether or not this impact is in fact real), that may have a significant influence on future behaviour. There is a wide literature on anglers' broader preferences, which shows that their motivations combine catch and non-catch elements and relate to both the angling activity specifically and to the broader outdoor recreational experience [e.g. 21]. However, past success at a site, combined with the variety of species present and friends' recommendations were better predictors of the likelihood of anglers visiting offshore oil structures in Gulf of Mexico than factors related to access such as distance from shore and water depth $[5,6]$. When analysing the use of artificial reefs more broadly, Milon [22] also found that anglers expectations of a greater likelihood of catching fish and their previous catch success were more important factors in their use of a particular site than its proximity to shore.

Even taking account of the positive angling experiences reported from OWF sites, there is little evidence that OWF development will have a significant economic impact (either positive or negative) on the recreational sector. While anglers were willing to exploit OWFs within their regular fishing areas, they appeared to have little appetite for travelling beyond these areas in order to access OWF sites. This evidence supports an earlier assertion that there is unlikely to be a large market demand for charter angling trips to OWFs, even if they were shown to support good fishing [10]. It is also possible that the bias in respondents towards more avid anglers leads to an overstatement of willingness of the group more generally to fish at OWF sites. It has previously been shown that frequency of participation in the sport is a significant determinant of the likelihood of anglers choosing artificial reef sites [22]. Finally, most recreational angling opportunities are likely to be limited to OWFs in inshore areas, which are a relatively small proportion of the predicted total number of OWFs: the 18 developments that are in construction or consented for the UK, which are expected to comprise some 1400 individual turbines, will be located on average $19 \mathrm{~nm}$ from the coast (as calculated from data provided by [2].

The responses to the contingent behaviour questions suggest that anglers are unlikely to change the frequency of their visits to an area following OWF construction. Even if they do elect to cease fishing at the site, they will most likely substitute an alternative angling location. This suggests the worst case scenario considered for recreational fishing in Scotland, in which angling within the OWF footprint ceases and is not replaced by effort elsewhere [15], is unlikely to be realised. However, there is the possibility that specific recreational fisheries could incur negative economic impacts. Tope fisheries are worth about £10million per year to parts of Southwest Scotland, with one particular annual angling event generating some $£ 50,000$ for the local economy [15]. Anglers in this study consistently reported a decline in tope at OWF sites, which may suggest a cause for concern. Field studies on the implications of OWFs for this species appear to be absent from the literature [16].

Beyond their perceptions of the direct effects on fishing opportunities, anglers tend to share the opinions of the general public with respect to OWFs. Both groups have concerns about the impact of the structures on 
the view, their reliability and cost, and tend to exhibit preferences for other forms of low-carbon energy, particularly solar power [23-26]. A lack of trust in developers and regulators as well as beliefs amongst anglers that the consultation process is inadequate reiterate similar concerns that have been raised previously, particularly by commercial fishers [10,11]. The prevalence of “don't know" responses to questions on certain OWF issues (such as cost and wildlife impacts) as well as anglers' uncertainty as to whether they are permitted to fish within the proximity of OWFs further suggests a need for better information and communication. Anglers can be a difficult group to engage however: clubs, specialist media and the angling representatives of the Inshore Fisheries and Conservation Authorities were used to disseminate information and recruit participants for this survey, but many anglers undertake their sport individually or in small groups without any institutional engagement. Such individuals are extremely difficult to identify and to sample costeffectively in a comprehensive and representative manner.

It seems unlikely that, at the present, recreational fisheries at OWFs in the UK will approach the levels of exploitation seen for offshore oil and gas structures in the Gulf of Mexico, which are the principal destination for a large majority of fishers in that region and attract high densities of sportfishing boats [5-7]. There are few other international comparisons which can be made, as there is an absence of information on interactions between recreational anglers and OWFs beyond occasional anecdote [e.g. 27]. However, offshore wind energy is relatively young sector: less than 100 turbines have been operational in UK waters for more than a decade, while over 1000 have been in place for 5 years or less. This may affect the likelihood of anglers visiting the sites; the age of artificial reef sites in Florida was a significant factor in the frequency with which anglers used them [22]. This issue perhaps explains in part why the OWF visited most frequently by anglers responding to our survey was Gunfleet Sands (which has been operational since 2009), although additional data would be required to assess the relationship between angling frequency and specific site characteristics. There remains the potential to reassess opportunities for co-location of recreational angling and OWFs as the reefs around the structures mature and the implications of OWFs for target species are better understood. The results of this study serve as a baseline of the perceptions of anglers against which such future reassessments can be compared.

\section{Conclusions}

In summary, anglers appear to be broadly favourable towards OWFs in general, and have successfully utilised OWFs for recreational purposes. However, those who have fished in the proximity of OWFs have mixed opinions on the effect of the developments on their recreational experience, and there is no evidence that future OWF construction would significantly affect recreational angling behaviour (either positively or negatively). Also, recreational anglers feel they are poorly informed and inadequately consulted with regard to OWF developments, an issue that should be addressed given the size and economic importance of the sector. 


\section{Acknowledgements}

This research formed part of the Quantifying benefits and impacts of fishing exclusion zones around Marine Renewable Energy Installations (QBEX) programme and was supported by the UK Research Councils under Natural Environment Research Council award NE/J012327/1.

\section{References}

[1] Global Wind Energy Council. 2016. Global Wind Report. Annual Market Update 2015. April 2016. http://www.gwec.net/publications/global-wind-report-2/ Accessed 25 May 2016

[2] 4C Offshore. Global Offshore Wind Farms database. http://www.4coffshore.com/windfarms/ Accessed 25 May 2016

[3] MMO. 2013. Strategic Scoping Report for marine planning in England. August 2013. Marine Management Organisation.

[4] Hooper, T. and Austen, M. 2014. The co-location of offshore windfarms and decapod fisheries in the UK: Constraints and opportunities. Marine Policy 43: 295-300

[5] Ditton, R. B., and Auyong, J. 1984. Fishing offshore platforms central Gulf of Mexico: an analysis of recreational and commercial fishing use at 164 major offshore petroleum structures. Government Reports, Announcements and Index, National Technical Information Service (NTIS), US Department of Commerce 84(21).

[6] Gordon, W. R. Jr. 1993. Travel characteristics of marine anglers using oil and gas platforms in the central Gulf of Mexico. Marine Fisheries Review 55(1):25-31.

[7] Stanley, D. R., and Wilson, C. A. 1989. Utilization of offshore platforms by recreational fishermen and scuba divers off the Louisiana coast. Bulletin of Marine Science 44(2):767-776.

[8] Hooper, T., Ashley, M. and Austen, M. 2015. Perceptions of fishers and developers on the co-location of offshore wind farms and decapods fisheries in the UK. Marine Policy 61: 16-22

[9] Reilly, K., O’Hagan, A.M. and Dalton, G. 2015. Attitudes and perceptions of fishermen on the island of Ireland towards the development of marine renewable energy projects. Marine Policy 58: 88-97.

[10] Mackinson, S., Curtis, H., Brown, R., McTaggart, K., Taylor, N., Neville, S. and Rogers, S. 2006. A Report on the Perceptions of the Fishing Industry into the Potential Socio-Economic Impacts of Offshore Wind Energy Developments on their Work Patterns and Income. Report by Centre for Environment Fisheries and Aquaculture Science (CEFAS). 62 pp

[11] Gray, T., Haggett, C. and Bell, D., 2005. Offshore wind farms and commercial fisheries in the UK: A study in Stakeholder Consultation. Ethics Place and Environment 8(2): 127-140. 
[12] Gray, M., Stromberg, P-L., Rodmell, D. 2016. Changes to fishing practices around the UK as a result of the development of offshore windfarms - Phase 1. The Crown Estate, $121 \mathrm{pp}$.

[13] Richardson, L. (Ed). 2015. UK Sea Fisheries Statistics 2015. Marine Management Organisation and Office For National Statistics.

[14] Armstrong, M., Brown A., Hargreaves, J., Hyder, K., Pilgrim-Morrison, S., Munday, M., Proctor, S., Roberts, A., and Williamson, K. 2012. Sea Angling 2012 - a survey of recreational sea angling activity and economic value in England. Report to the Department of the Environment, Food and Rural Affairs. November 2013.

[15] ABPMer. 2011. Economic Assessment of Short Term Options for Offshore Wind Energy in Scottish Territorial Waters: Costs and Benefits to Other Marine Users and Interests. Report to Marine Scotland. The Scottish Government, Edinburgh 2011. 141pp

[16] Hooper, T., Beaumont, N., \& Hattam, C. In Press. The implications of energy systems for ecosystem services: A detailed case study of offshore wind. Renewable and Sustainable Energy Reviews.

[17] Fujii, T. 2015. Temporal variation in environmental conditions and the structure of fish assemblages around an offshore oil platform in the North Sea. Marine environmental research 108:69-82.

[18] Jørgensen, T., Løkkeborg, S., and Soldal, A. V. 2002. Residence of fish in the vicinity of a decommissioned oil platform in the North Sea. ICES Journal of Marine Science 59:S288-S293.

[19] Løkkeborg, S., Humborstad, O. B., Jørgensen, T., and Soldal, A. V. 2002. Spatio-temporal variations in gillnet catch rates in the vicinity of North Sea oil platforms. ICES Journal of Marine Science, 59: S294-S299.

[20] Soldal, A. V., Svellingen, I., Jørgensen, T., and Løkkeborg, S. 2002. Rigs-to-reefs in the North Sea: hydroacoustic quantification of fish in the vicinity of a "semi-cold" platform. ICES Journal of Marine Science: Journal du Conseil, 59: S281-S287.

[21] Arlinghaus, R. 2006. On the apparently striking disconnect between motivation and satisfaction in recreational fishing: the case of catch orientation of German anglers. North American Journal of Fisheries Management 26(3): 592-605.

[22] Milon, J.W., 1989. Artificial marine habitat characteristics and participation behavior by sport anglers and divers. Bulletin of Marine Science, 44(2), pp.853-862.

[23] Hattam, C., Hooper, T. and Beaumont, N. 2015. Public Perceptions of Offshore Wind Farms, The Crown Estate. 50pp.

[24] Devine-Wright, P. and Howes, Y. 2010. Disruption to place attachment and the protection of restorative environments: A wind energy case study. Journal of Environmental Psychology 30(3): 271-280. 
[25] Waldo, ^. 2012. Offshore wind power in Sweden-A qualitative analysis of attitudes with particular focus on opponents. Energy Policy 41: 692-702.

[26] DECC. 2016. Public Attitudes Tracking Survey. Wave 17: Headline findings Department for Energy and Climate Change. https://www.gov.uk/government/statistics/public-attitudes-tracking-surveywave-17 Accessed 5 October 2016.

[27] Vandendriessche, S., Hostens, K., Courtens, W., and Stienen, E. 2013. Fisheries activities change in the vicinity of offshore wind farms. p 81-85 In: Degraer, S., Brabant, R., \& Rumes, B. Environmental Impacts of Offshore Wind Farms in the Belgian Part of the North Sea: Learning From the Past to Optimise Future Monitoring Programs. Royal Belgian Institute of Natural Sciences, Brussels. 